\title{
Influência de temperatura e taxas de aquecimento na resistência mecânica, densidade e rendimento do carvão da madeira de
} Eucalyptus cloeziana

\author{
Evair Antônio Siebeneichler ${ }^{1}$, Liovando Marciano da $\operatorname{Costa}^{1}$, Natália Aragão Figueredo ${ }^{1 \star}$, Jairo \\ Tronto $^{2}$, Pablo Azevedo Rocha ${ }^{1}$ \\ ${ }^{1}$ Departamento de Solos, Universidade Federal de Viçosa, Viçosa - Brasil. \\ ${ }^{2}$ Departamento de Química, Universidade Federal de Viçosa, Viçosa - Brasil.
}

\begin{abstract}
RESUMO O uso da pirólise como forma de aproveitamento energético da biomassa e resíduos orgânicos vem sendo avaliada como uma alternativa aos combustíveis fósseis. O carvão gerado neste processo é altamente recalcitrante, e sua incorporação ao solo pode contribuir para o sequestro de carbono, além de também melhorar a qualidade do solo de uso agrícola. Este trabalho avaliou o efeito de diferentes condições de pirólise sobre as características físicas, como resistência mecânica, densidade e rendimento gravimétrico do carvão produzido. Para isso, amostras de madeira de Eucalyptus cloeziana foram pirolisadas em nove temperaturas entre $300 \mathrm{e} 700^{\circ} \mathrm{C}$, sob três taxas de aquecimento $\left(5,22,5 \mathrm{e} 40^{\circ} \mathrm{C} \mathrm{min}{ }^{-1}\right)$. A produção de líquido pirolenhoso atinge o máximo de rendimento em temperaturas entre de 400 e $700^{\circ} \mathrm{C}$ na taxa de aquecimento de $5^{\circ} \mathrm{C} \cdot \mathrm{min}^{-1}$. Com o aumento da temperatura e da taxa de aquecimento, aumenta a ocorrência de rupturas na estrutura dos carvões, com consequente redução da resistência física destes.
\end{abstract}

Palavras-chave: carbono; estabilidade térmica; energia.

\section{Influence of temperature and heating rates on mechanical re- sistance, density and yield of the wood charcoal of Eucalyptus cloeziana}

\begin{abstract}
The use of pyrolysis as a way of energetic use of biomass and organic wastes has been evaluated as an alternative to fossil fuels. The carbon generated in this process is highly recalcitrant, and its incorporation into the soil can contribute to the carbon sequestration, as well as improving soil quality for agricultural use. This work evaluated the effect of different pyrolysis conditions on the physical characteristics, such as mechanical strength, density and gravimetric yield of the charcoal produced. For this, samples of Eucalyptus cloeziana wood were pyrolyzed at nine temperatures between 300 and $700{ }^{\circ} \mathrm{C}$, under three heating rates $\left(5,22.5\right.$ and $\left.40^{\circ} \mathrm{C} \mathrm{min}^{-1}\right)$. The production of pyrolignal liquid reaches the maximum yield at temperatures between 400 and $700{ }^{\circ} \mathrm{C}$ with heating rate of $5^{\circ} \mathrm{C} \mathrm{min}^{-1}$. With the increase of temperature and the rate of heating, it increases the occurrence of ruptures in the structure of the charcoals, with consequent reduction of their physical resistance.
\end{abstract}

Keywords: carbon; thermal stability; energy.

\section{Introdução}

O aproveitamento energético da biomassa e de resíduos orgânicos como fontes de energia vem sendo avaliada como uma alternativa aos combustíveis fósseis diante dos inúmeros impactos negativos e poluições decorrentes, principalmente na emissão de $\mathrm{CO}_{2}$. Dentro desta perspectiva, as novas formas de aproveitamento energético da biomassa envolvem a conversão desta em combustíveis líquidos (álcool, biodiesel, e líquido pirolenhoso) ou gasosos (metano, hidrogênio, e monóxido de carbono) (DEMIRBAS, 2009). Uma alternativa promissora que vem sendo proposta é o uso do carvão vegetal produzido pela conversão da biomassa em líquido pirolenhoso ou gases combustíveis através da pirólise. 
Além da importância energética, o carvão vegetal vem sendo amplamente estudado como uma forma efetiva de conter o carbono, apresentando também potencial para melhorar a fertilidade e influenciar as propriedades físicas, químicas e biológicas dos solos (LEHMANN et al., 2009; HERATH et al., 2013. O uso promissor do carvão está relacionado às suas características físicas e químicas, como capacidade de reter íons, porosidade, superfície específica, bem como à sua resistência física e química (GLAB et al., 2016).

Os fatores que mais influenciam estas propriedades são as características do material precursor, como porosidade, composição química, densidade que influenciam na qualidade do carvão vegetal além da taxa de aquecimento, tempo de reação e a temperatura em que ocorre a pirólise (VIEIRA et al., 2013). A temperatura final de carbonização desempenha um papel muito importante nas diversas reações químicas envolvidas durante a pirólise e influenciam nas características químicas e físicas dos produtos gerados (HEIN et al.,2009).

Para a maioria das biomassas, o aumento da temperatura e do tempo de reação reduz a produção final tanto de compostos voláteis e líquidos, como a de carvão vegetal. Porém, estes fatores associados favorecem o aumento da organização estrutural do carvão produzido, aumentando a resistência física e química deste (BYRNE; NAGLE, 1997). Num primeiro estágio, a temperatura e o tempo de reação a decomposição dos compostos menos resistentes, alterando a estrutura do material. O prolongado aquecimento e altas temperaturas podem causar o colapso das paredes celulares, levando ao aumento do volume de poros, porém reduzindo a área superficial específica (ZHANG et al., 2010).

Desta forma, com o uso da pirólise para o aproveitamento da biomassa e de outros resíduos orgânicos, três grandes benefícios são alcançados: produção de energia, manejo de resíduos, e diminuição da poluição ambiental (LEHMANN; JOSEPH, 2009). Para contribuir para os estudos relacionados à pirólise da biomassa e a recalcitrância dos carvões vegetais, o presente estudo tem como objetivo analisar a influência da taxa de aquecimento e da temperatura de pirólise da madeira de eucalipto (Eucalyptus cloeziana) sobre o rendimento dos produtos da pirólise e sobre características físicas dos carvões produzidos que vão contribuir na estabilidade térmica e na recalcitrância destes materiais.

\section{Material e Métodos}

\section{Material e processo de pirólise}

O material utilizado foi o proveniente da madeira de $\mathrm{Eu}$ calyptus cloeziana obtidas a partir de um plantio de 7 anos de idade, em peças com dimensões de $10 \times 1 \times 1 \mathrm{~cm}$. As amostras de madeira foram secas a $105^{\circ} \mathrm{C}$ por $24 \mathrm{~h}$ em estufa com circulação forçada de ar. O processo de pirólise foi realizado em forno tipo mufla, dentro de um cadinho aço inox que conta com uma abertura na parte superior para permitir a saída dos voláteis, restringindo assim a entrada de oxigênio no seu interior.

Foram avaliadas nove temperaturas de pirólise (TP), de $300,350,400,450,500,550,600,650$ e $700^{\circ} \mathrm{C}$, com intervalos de $50^{\circ} \mathrm{C}$, e três taxas de aquecimento (TA) para cada uma destas temperaturas, sendo elas $5,22,5$, e $40{ }^{\circ} \mathrm{C} \cdot \mathrm{min}^{-1}$ (TA5, TA22,5 e TA40).

Para todas as temperaturas, o tempo de residência na temperatura final de pirólise foi de 15 min. Após este tempo, foi aguardada a redução da temperatura interna da mufla até 100 ${ }^{\circ} \mathrm{C}$ para realizar a retirada do carvão. Em seguida, o carvão produzido foi armazenado em dessecador, até que todos os tratamentos dentro de uma repetição tivessem sido realizados, considerado o fator tempo como bloco. Este procedimento se faz necessário porque o carvão sofre reações de oxidação em contato com a atmosfera, alterando a quantidade de grupos superficiais ativos (BOEHM, 2008). 
O líquido pirolenhoso recuperado foi recolhido para a determinação da quantidade produzida. Os rendimentos gravimétricos do carvão, líquido pirolenhoso e gases não condensáveis foram calculados em relação à massa seca da madeira. Os gases, voláteis não condensáveis foram estimados por diferença: Gases = massa inicial da madeira - (massa de carvão + massa de bio-óleo).

\section{Análise termogravimétrica (TGA)}

Foi realizada a análise termogravimétrica em atmosfera de nitrogênio $\left(\mathrm{N}_{2}\right)$ da madeira e dos carvões produzidos nas TP de 300,500 e $700{ }^{\circ} \mathrm{C}$, e TA de $22,5^{\circ} \mathrm{C} \min ^{-1}$. Nestes carvões selecionados foram realizadas análises termogravimétricas acoplada a análise térmica diferencial (TG-DTA) em aparelho Netzsch STA 409EP, com atmosfera de $\mathrm{N}_{2}$, taxa de aquecimento de $10{ }^{\circ} \mathrm{C} \mathrm{min}{ }^{-1}$ e fluxo de gás de $100 \mathrm{~mL} \mathrm{~min}^{-1}$.

\section{Análises físicas e mecânicas dos carvões produ-}

\section{zidos}

A resistência mecânica do carvão foi avaliada de maneira similar ao teste de tamboramento comumente utilizado na indústria de carvão vegetal. Todo o carvão produzido nos tratamentos foi colocado em garrafa PET de $500 \mathrm{~mL}$, e na sequência colocados para agitar por $4 \mathrm{~h}$ em agitador rotatório tipo Wagner, a 50 rpm. Após este tempo, os carvões foram separados em duas frações, uma maior e outra menor que2 $\mathrm{mm}$ de diâmetro médio. As duas frações foram secas em estufa $\left(105^{\circ} \mathrm{C}, 24 \mathrm{~h}\right)$ e pesadas.

A densidade global foi calculada pela divisão da massa pelo volume das peças de carvão após a pirólise, através da equação:

$$
\mathrm{D}=(\text { massa do carvão vegetal }) \div
$$

(volume de carvão + volume de poros).
A densidade de partícula (massa de carvão/volume de carvão) foi estimada com as amostras moídas, pelo método do balão volumétrico com álcool, a qual consistiu na pesagem de $1 \mathrm{~g}$ de carvão ou madeira em balão volumétrico de $25 \mathrm{~mL}$, seguido da adição de cerca de $10 \mathrm{~mL}$ de álcool. O tempo de penetração do álcool nas amostras foi de $1 \mathrm{~h}$, com agitações manuais dos balões a cada 10 min; após esse tempo, o balão era completado com álcool e imediatamente pesado.

Os dados obtidos para as variáveis estudadas foram analisados pela análise de variância (teste de F) e quando necessário, as médias das temperaturas foram comparadas pelo teste t a $5 \%$ de significância (DMS $5 \%$ ).

\section{Microscopia eletrônica de varredura (MEV)}

Foram selecionadas peças que mais diferenciavam dos carvões produzidos a 300,500 e $700{ }^{\circ} \mathrm{C}$, nas três TA em duas formas: em pó e da superfície dos carvões antes da moagem. Foi aplicada sobre as amostras uma cobertura de ouro para garantir condutividade e utilizado o aparelho LEO 1430VP, no Núcleo de Microscopia e Microanálise da Universidade Federal de Viçosa.

\section{Resultados e Discussão}

\section{Análise termogravimétrica em atmosfera de $\mathrm{N}_{2}$}

$\mathrm{Na}$ fase inicial do aquecimento das amostras, nota-se um evento endotérmico, comumente associado à perda de água do material. A quantidade de água contida nos carvões aumentou com o aumento da TP, correspondendo a 4,4, 5,2 e $6,4 \%$ da massa da amostra nos carvões produzidos a 300, 500 e $700{ }^{\circ} \mathrm{C}$, respectivamente (Figura 1). Este resultado pode estar associado à maior porosidade do carvão produzido a 700 ${ }^{\circ} \mathrm{C}$, como consequência da perda de massa adicional que sofreu em relação aos outros dois carvões, devido às reações de 
termodecomposição secundárias. A maior umidade da madeira $(9,1 \%$ da massa) está associada ao caráter hidrofílico das hemiceluloses e celulose, as quais já haviam sofrido alguma degradação térmica no carvão produzido a $300^{\circ} \mathrm{C}$.

O padrão de termodecomposição do carvão produzido a $300{ }^{\circ} \mathrm{C}$ foi semelhante ao da madeira, entretanto, apresentou uma menor taxa de perda de massa no primeiro evento de termodecomposição $\left(290{ }^{\circ} \mathrm{C}\right)$, região característica da termodecomposição da hemicelulose. A perda de massa neste evento, calculado com base na massa das amostras sem o teor de umidade, foi de 23,4 e $18,6 \%$ para madeira e carvão produzido a $300^{\circ} \mathrm{C}$, respectivamente.
O segundo evento de termodecomposição teve pico em $356,7^{\circ} \mathrm{C}$ na madeira e em $360,2^{\circ} \mathrm{C}$ no carvão produzido a $300^{\circ} \mathrm{C}$, e resultou na redução de 50,8 e $56,0 \%$ da massa seca, respectivamente. A maior temperatura em que ocorreu o pico para o carvão produzido a $300^{\circ} \mathrm{C}$ é devido à transformação parcial que a celulose já sofreu com o tratamento térmico, aumentando a sua resistência térmica (WOOTEN et al., 2004). Já a maior perda de massa desse carvão associado a este segundo evento, deve ter ocorrido em função do seu enriquecimento em celulose, causado pela prévia decomposição da hemicelulose. Esta hipótese é reforçada pelo padrão de termodecomposição idêntico entre a madeira e o carvão,

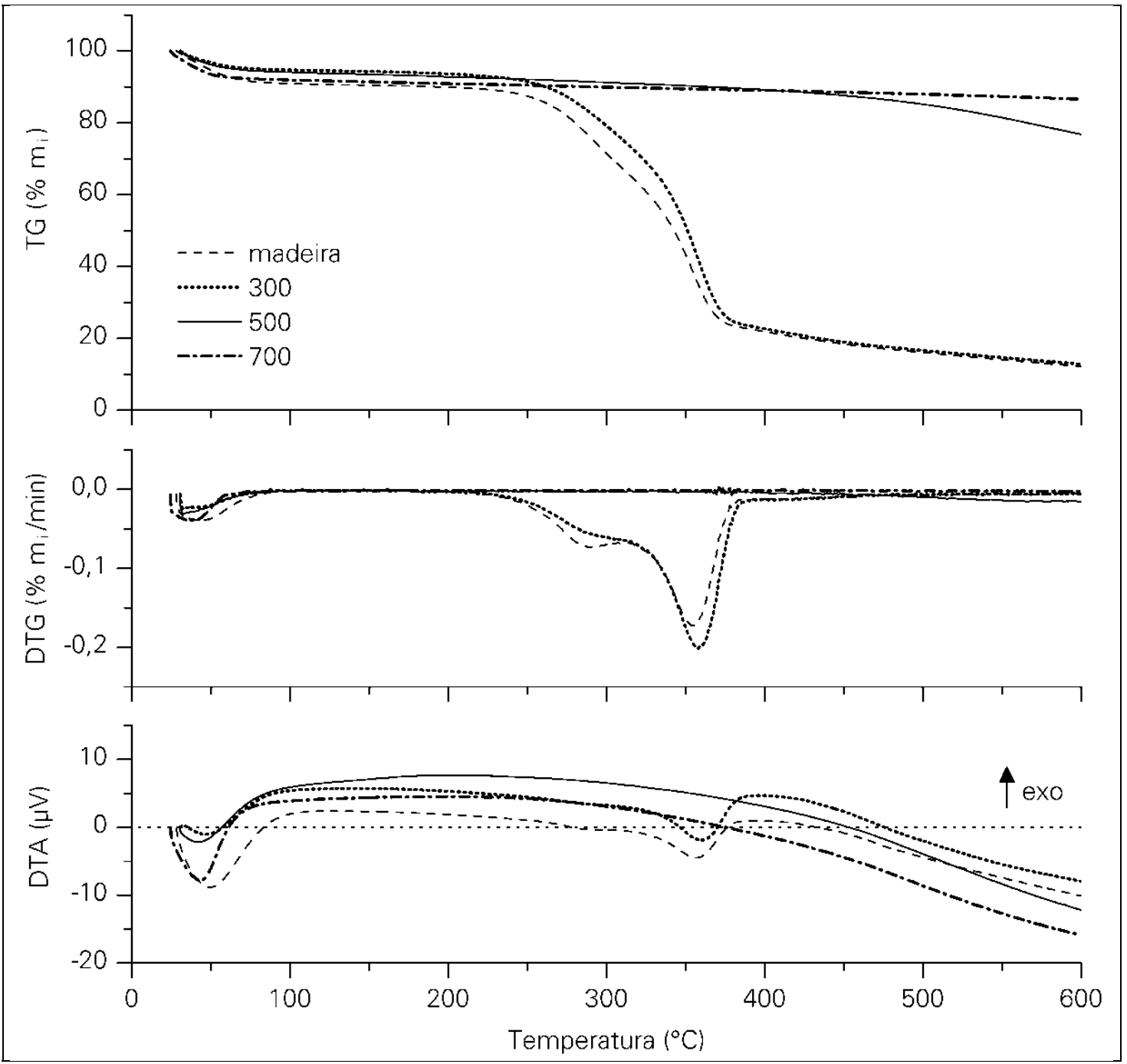

Figura 1. Análise termogravimétrica (TG, DTG e DTA) dos carvões TP300-TA22,5, TP500-TA22,5 e TP700-TA22,5 e da madeira em atmosfera de $\mathrm{N}_{2} \cdot \mathrm{m}_{\mathrm{i}}=$ massa inicial.

Figure 1. Thermogravimetric analysis (TG, DTG and DTA) of the TP300-TA22,5 charcoal, TP500, TP700 and TA22,5-TA22,5 and $\operatorname{wood} \mathrm{N} 2 . \mathrm{mi}=$ initial mass. 
nas temperaturas superiores, que culminaram com a perda de massa adicional de 13,3 e 12,4\%, respectivamente, com o aquecimento até $600^{\circ} \mathrm{C}$.

O rendimento na análise termogravimétrica foi de 12,4

e $13,1 \%$ para a madeira e o carvão produzido a $300{ }^{\circ} \mathrm{C}$, quantidade notavelmente menor do que a obtida no ensaio em laboratório. O resultado deve-se a dois fatores principais: ao fluxo de gás durante a análise termogravimétrica, que transporta os produtos da pirólise para fora do local de reação a medida que são produzidos; e o menor tamanho das partículas de amostra (madeira ou carvão) utilizadas na análise termogravimétrica $(\varnothing<0,105 \mathrm{~mm})$, que facilita a saída dos produtos da pirólise do interior da partícula, reduzindo a ocorrência das reações de termodecomposição secundárias.

Os carvões produzidos a 500 e $700{ }^{\circ} \mathrm{C}$ não apresentaram eventos de termodecomposição tão nítidos como os da madeira e do carvão produzido em $300{ }^{\circ} \mathrm{C}$. As perdas de massa destes foram de 27,5 e 9,4 \%, respectivamente, mostrando as reações de termodecomposição não haviam chegado a um equilíbrio com o tempo de pirólise usado no ensaio. $\mathrm{O}$ carvão produzido a $500{ }^{\circ} \mathrm{C}$ apresentou um aumento da taxa de perda de massa apenas quando a temperatura foi elevada acima daquela com a qual foi produzido. Este resultado indica que este carvão é menos resistente à termodecomposição que o produzido em temperaturas maiores, e colaboram com os dados de rendimento gravimétrico de carvão, que mencionam uma contínua e lenta termodecomposição destes com o aumento de temperatura.

Os eventos térmicos associados à termodecomposição da hemicelulose e da celulose são endotérmicos, enquantoque as reações de termodecomposição dos seus produtos são exotérmicos. Com a continuação do aquecimento das amostras após a faixa de temperatura em que ocorreram es- tas reações exotérmicas, o processo global passou a ser endotérmico. Esse evento pode estar associado à fusão e ao rearranjo estrutural dos compostos sólidos restantes.

\section{Rendimento gravimétrico de carvão, líquido pirolenhoso e gases não condensáveis}

Para as três taxas de aquecimento (TA), a conversão da madeira em líquido pirolenhoso aumentou até a faixa de 400 ${ }^{\circ} \mathrm{C}$, após a qual não houve novos incrementos. Esses rendimentos do líquido pirolenhoso e dos gases condensáveis corroboram com os dados de Valente et al. (1985), que identificaram maiores rendimentos desses produtos na carbonização de Eucalyptus entre $300^{\circ} \mathrm{C} \mathrm{e} 450^{\circ} \mathrm{C}$ e a partir deste valor ocorreu uma estabilização.

A menor temperatura para alcançar maior produção de líquido pirolenhoso foi de $400{ }^{\circ} \mathrm{C}$ para a TA5, e $450{ }^{\circ} \mathrm{C}$ para as TA22,5 e TA40, sendo as respectivas taxas de conversão obtidas de aproximadamente 41,2, 46,5 e 48,1 \% (Figura 2). O menor rendimento com a TA5 deve-se a reações secundárias de decomposição térmica do líquido pirolenhoso produzido.

De acordo com Oliveira et al. (2010), as maiores taxas de aquecimento acarretam em diminuição no rendimento em carvão, nos teores de materiais voláteis e nos valores de densidade aparente. Quando a pirólise é conduzida a uma baixa taxa de aquecimento, a temperatura demora a atingir um determinado valor, no qual ocorre uma maior taxa de decomposição térmica dos componentes da biomassa, e há uma reduzida velocidade de saída dos compostos recém-formados do sistema. Ao permanecerem no sistema sob alta temperatura, os compostos recém-formados sofrem novas reações de decomposição (reações secundárias), sendo convertidos principalmente em gases, como $\mathrm{CO}_{2}, \mathrm{CO}$, e $\mathrm{H}_{2} \mathrm{O}$ de menor massa molecular e em carvão (RANZI et al., 2008; GARCIA-PEREZ et al., 2008). 

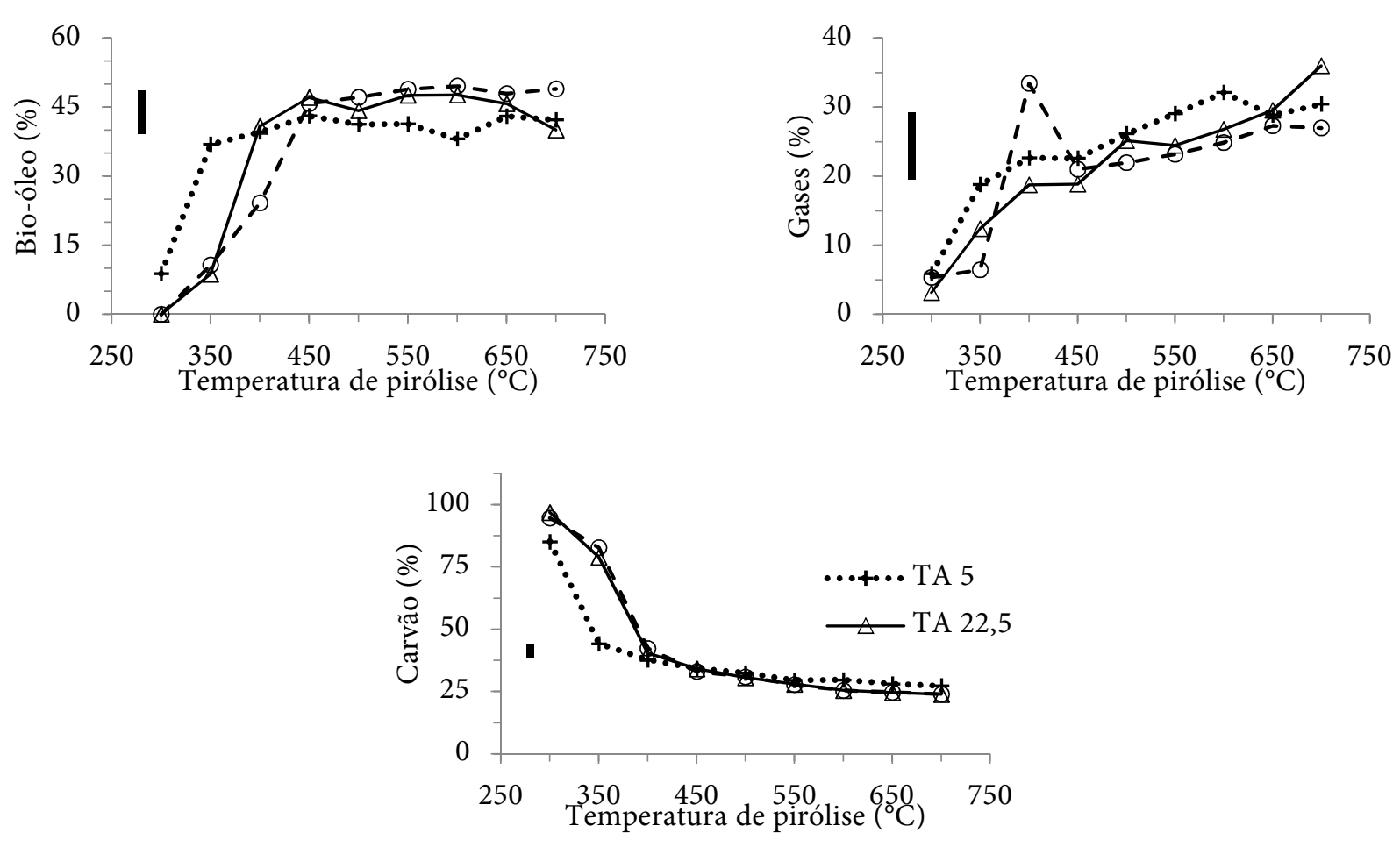

Figura 2. Rendimento gravimétrico de líquido pirolenhoso, gases não condensáveis e carvão em função da taxa de aquecimento e da temperatura de pirólise. Barra = DMS $5 \%$. Legenda: TA: taxa de aquecimento.

Figure 2. Yield gravimetric bio-oil, non-condensable gases and charcoal as a function of to the heating rate and the pyrolysis temperature. Bar $=5 \%$ DMS.

O rendimento gravimétrico do carvão vegetal foi decrescente, chegando a $25 \%$ a $700{ }^{\circ} \mathrm{C}$. Estes dados são semelhantes aos apresentados por Vieira et al., 2013, que identificaram uma variação de 27 e 34 \% no rendimento da carbonização entre $500{ }^{\circ} \mathrm{C}$ e $900{ }^{\circ} \mathrm{C}$. Esse efeito da temperatura sobre as reações químicas que ocorrem durante o processo de pirólise que, por conseguinte, causou o aumento dos gases não condensáveis.

A redução do rendimento de carvão se deve principalmente à termodecomposição da hemicelulose e da celulose. Já nas temperaturas superiores, predominaram as reações de termodecomposição da lignina e dos resíduos sólidos da celulose e hemicelulose. A celulose, a hemicelulose e a lignina são os principais constituintes da biomassa levados em conta nos estudos da pirólise como forma de aproveitamento energético da biomassa. A hemicelulose é a menos estável desses três componentes, e sua termodecomposição ocorre na faixa de $150-350^{\circ} \mathrm{C}$, e com taxa máxima em torno de $270{ }^{\circ} \mathrm{C}$. A celulose possui composição química semelhante à hemicelulose, mas devido ao seu arranjo cristalino, é mais resistente à termodecomposição, que ocorre na faixa de $275-400{ }^{\circ} \mathrm{C}$, com taxa máxima em torno de $350^{\circ} \mathrm{C}$ (ROWELL et al., 2005).

O carvão também sofre reações secundárias de termodecomposição. Isto é evidente nas temperaturas superiores àquelas em que se atingiu a máxima produção do líquido pirolenhoso, onde se observa o aumento do rendimento de gases e redução do rendimento de carvão (Figura 2). Assim, as reações de decomposição secundárias contribuem tanto para o aumento do rendimento de carvão com a redução da TA, como para a conversão de carvão em gases nas três TA.

$\mathrm{Na}$ temperatura de $400^{\circ} \mathrm{C}$, o líquido pirolenhoso produzido apresentou o maior teor de oligômeros e a maior viscosidade, e por trabalhar com partículas de menor tamanho (0,1-0,6 mm), obtiveram conversões de $63 \%$ e $18 \%$ da massa 
da madeira em líquido pirolenhoso e carvão, respectivamente.

\section{Resistência física e densidade}

Nas três taxa de aquecimento, a resistência física do carvão reduziu com o aumento da $\mathrm{TP}$ até $500{ }^{\circ} \mathrm{C}$. A partir desta temperatura, nas TA22,5 e TA40 não houve alteração significativa da resistência, sendo observada um rendimento médio de finos de 32 e $33 \%$, respectivamente, entre os carvões produzidos acima de $500^{\circ} \mathrm{C}$. Já para os carvões produzidos na TA5, o rendimento de finos atingiu $20,7 \%$ com a pirólise a $500{ }^{\circ} \mathrm{C}$, e diminui gradativamente para $16,6 \%$ com a pirólise a $700{ }^{\circ} \mathrm{C}$, demonstrando que a redução da taxa de aquecimento favoreceu o rendimento de finos no carvão.

A redução da resistência física é devida à termodecomposição dos principais constituintes da madeira (celulose, hemi- celulose e lignina) (VIEIRA et al., 2013). A celulose geralmente está presente em grandes quantidades e é o polímero com maior ocorrência nas madeiras, devido ao seu alto grau de polimerização e de orientação nas microfibrilas (cristalinidade), é considerada a principal responsável pela resistência física desse material. A hemicelulose serve basicamente como matriz para a celulose, e a lignina atua na união entre as fibras da madeira, conferindo rigidez e dureza à parede celular (WINANDY; ROWELL, 2005).

No entanto, apenas a degradação térmica dos componentes da madeira não justifica toda a alteração da resistência física dos carvões, outros fatores como a densidade e a estrutura morfológica do carvão são importantes.

A estimativa da densidade pelo método do balão volumétrico com álcool, aqui denominada de densidade de partículas, não possibilita distinguir claramente qualquer tendência
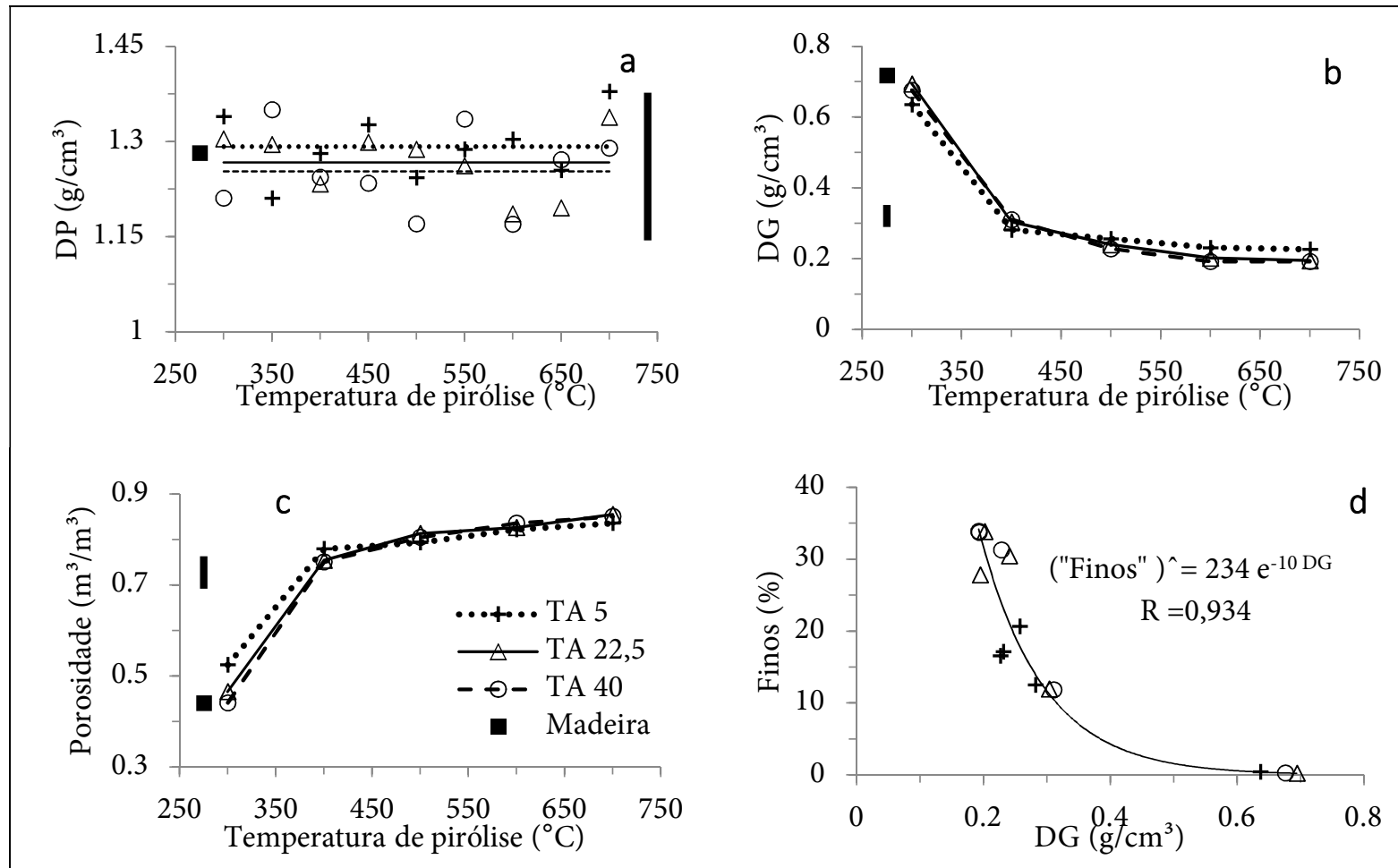

Figura 3. Rendimento de finos em porcentagem da massa. Barra = DMS 5 \%. Legenda: densidade de partícula: - DP (b), densidade global - DG (c), largura média das peças de carvão (d), porosidade (e) e correlação entre proporção de finos e densidade global (f). TA: taxa de aquecimento.

Figure 3. Yield of fines in percentage of mass (a), particle density - SD (b) overall density - DG (c) average width of charcoal pieces $(\mathrm{d})$, porosity $(\mathrm{e})$ and correlation between proportion of fines and bulk density (f). Bar $=5 \%$ DMS 
de comportamento com o aumento da TP ou entre as TA (Figura 3a). No entanto, o aumento da densidade de partículas com o aumento da TP é devido à perda dos compostos voláteis da madeira e, principalmente, com o concomitante aumento da organização estrutural do carvão em relação à madeira.

Já a densidade global claramente reduziu com o aumento da TP, e não houve muita diferença entre as TA, exceto que a densidade dos carvões produzidos nas maiores temperaturas na TA5 foram ligeiramente maiores que os de TA22,5 e TA40 (Figura 3b). A maior densidade com a TA5 se deve ao maior rendimento gravimétrico de carvão e ao menor volume das peças de carvão produzidas na TA5 em relação as outras TA.

A porosidade seguiu a tendência inversa da densidade global (Figura 3c). A densidade global foi a única forma de densidade que teve correlação com a resistência física dos carvões (Figura 6D). A correlação encontrada foi do tipo exponencial, e pode ser explicada pela associação da perda de massa durante a pirólise com a densidade global dos carvões.

\section{Microscopia eletrônica de varredura (MEV) e}

\section{umidade dos carvões}

Foram realizadas imagens por MEV de amostras de carvão produzidas a 300,500 e $700^{\circ} \mathrm{C}$ nas três TA. Devido à semelhança entre os carvões da TA22,5 e TA40, apenas as fotos do último são apresentadas. Nas imagens de pouca diferença entre os carvões produzidos a $300{ }^{\circ} \mathrm{C}$ e o material precursor devido ao curto tempo de reação, o aquecimento da madeira até $300^{\circ} \mathrm{C}$. Morfologicamente é notável a ruptura da madeira em camadas de células, não havendo diferença significativa entre as taxas de aquecimento. Com o aquecimento acima de $500{ }^{\circ} \mathrm{C}$, a perda de massa devido a termodecomposição da celulose e hemicelulose já havia sido praticamente completada e como resultado destas reações, os carvões apresentaram grande cisalhamento da estrutura (Figura 4).
Nos carvões produzidos a 500 e $700{ }^{\circ} \mathrm{C}$ é possível observar o efeito da TA sobre a característica morfológica, em que a TA implicou em ruptura muito mais intensa da estrutura do carvão. Na TA22 observa-se que houve uma fusão dos compostos remanescentes da pirólise com o aquecimento da madeira, não sendo mais possível identificar os limites anteriores entre as diferentes camadas das paredes celulares (Figura 4). Provavelmente tenha sido essa fusão a responsável pelo evento endotérmico observado na curva de DTA com a elevação da temperatura das amostras analisadas acima de 500 ${ }^{\circ} \mathrm{C}$.

A partir das imagens de MEV, foi estimada a espessura das paredes celulares (Tabela 1). Houve a tendência da espessura da parede celular de reduzir com o aumento da TP. No entanto, a redução da espessura das paredes foi menos que proporcional à perda de massa causada pelo aumento da TP, sendo assim esperado um aumento da densidade de partícula do carvão. Já o efeito da TA sobre a espessura da parede celular não é muito claro, uma vez que se esperava maior semelhança entre os carvões produzidos nas TA22,5 e TA40. Estas informações poderão ser de grande utilidade para o estudo de carvões com histórico de formação desconhecida, possibilitando a inferência da severidade de queima que o material sofreu.

Tabela 1. Espessura da parede celular $(\mu \mathrm{m}$; média \pm 1 desvio padrão; $\mathrm{n}=12-19$ )

Table 1. Cell wall thickness (one, mean \pm 1 standard deviation, $\mathrm{n}=12-19$ )

\begin{tabular}{ccccc}
\hline & \multicolumn{5}{c}{$\mathrm{TA}\left({ }^{\circ} \mathrm{C} / \mathrm{min}\right)$} \\
\cline { 2 - 5 } $\mathrm{TP}\left({ }^{\circ} \mathrm{C}\right)$ & 5 & 22,5 & 40 & $\begin{array}{c}\text { Mé- } \\
\text { dia }\end{array}$ \\
\hline 300 & $4,0 \pm 0,6$ & $5,2 \pm 1,3$ & $3,8 \pm 0,7$ & 4,3 \\
500 & $3,2 \pm 0,9$ & $1,6 \pm 0,5$ & $1,8 \pm 0,6$ & 2,2 \\
700 & $1,9 \pm 0,3$ & $1,9 \pm 0,7$ & $1,6 \pm 0,2$ & 1,8 \\
\hline Média & 3,0 & 2,9 & 2,4 \\
\hline Madeira & \multicolumn{5}{c}{$3,6 \pm 0,6$} \\
\hline
\end{tabular}

Legenda: TP: temperatura de pirólise; TA: taxa de aquecimento. 


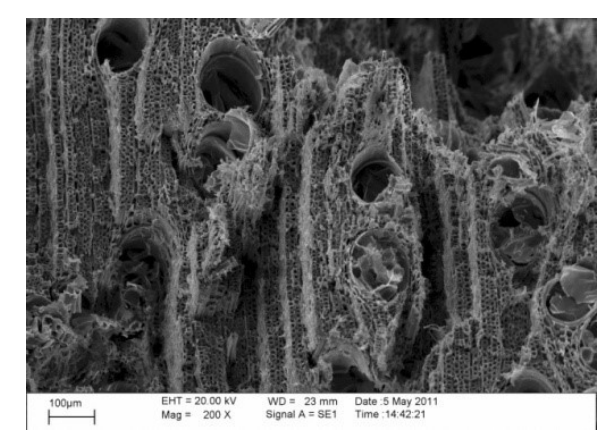

TP300-TA5

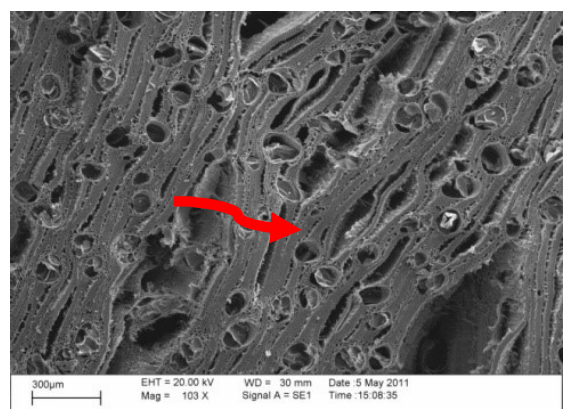

TP500-TA5

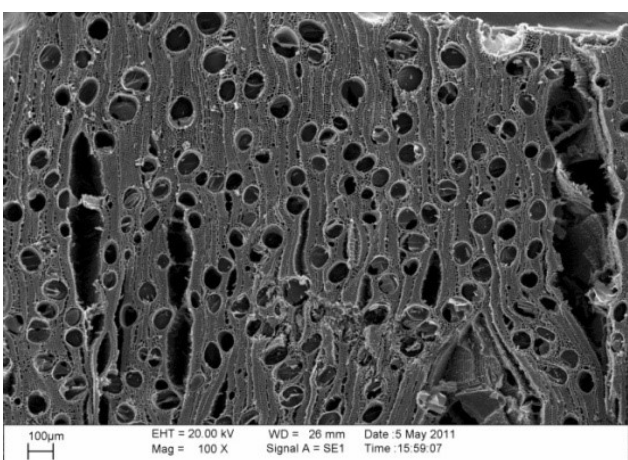

TP700-TA5

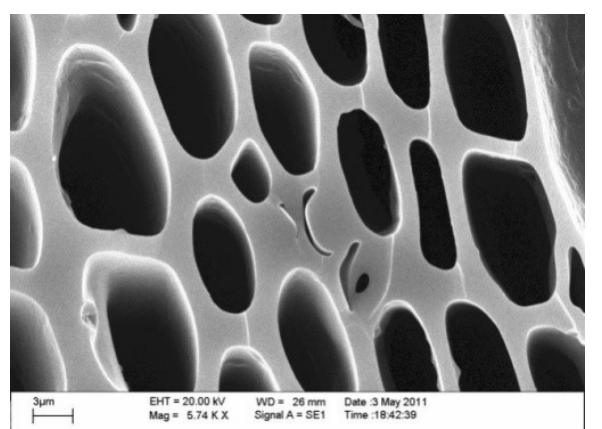

TP500-TA22,5

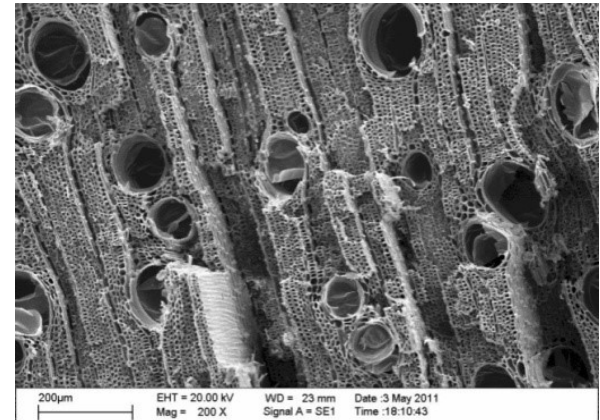

TP300-TA40

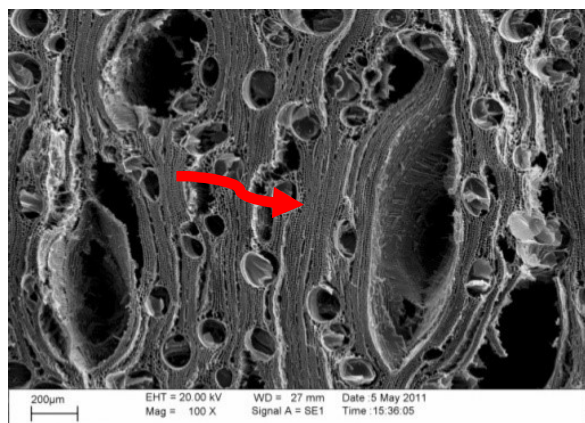

TP 500-TA40

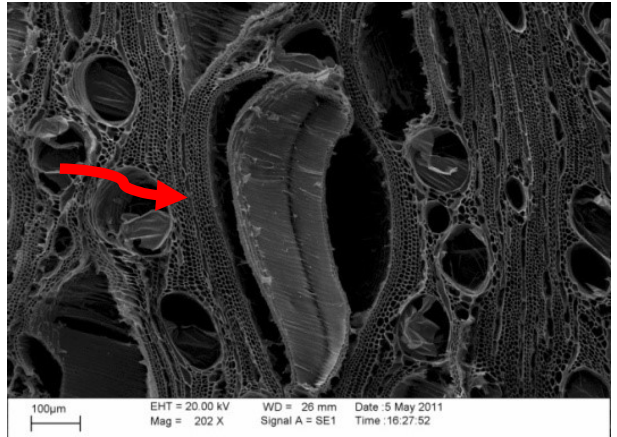

TP700-TA40

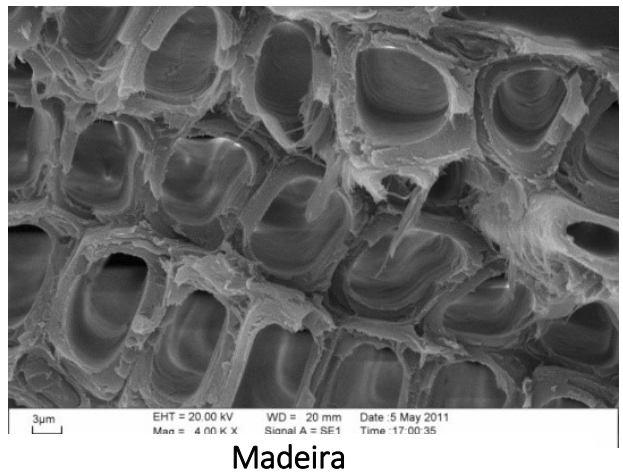

Figura 4. Imagens de microscopia eletrônica de varredura dos carvões TP300-TA5, TP300-TA40, TP500-TA5, TP500-TA40, TP700-TA5, TP700-TA40 e TP500-TA22,5, e da madeira. Legenda: TP: temperatura de pirólise; TA: taxa de aquecimento.

Figure 4. Images of scanning electron microscopy of the TP300-TA5 charcoal, TP300-TA40, TP500-TA5, TA40-TP500, TP700TA5, TA40-TP700 and TP500-TA22,5, and wood. 


\section{Estabilidade térmica e recalcitrância do carvão}

A temperatura em que a termodecomposição iniciou passou de aproximadamente $200{ }^{\circ} \mathrm{C}$ na madeira, para cerca de $410^{\circ} \mathrm{C}$ nos carvões produzidos em $700^{\circ} \mathrm{C}$. A estabilidade térmica dos carvões produzidos em $300{ }^{\circ} \mathrm{C}$ foi apenas ligeiramente superior à da madeira, com a maior diferença ocorrendo para o carvão produzido na TA5 (Figura 5). Desses, os produzidos na TA40 haviam perdido pouco do teor de hemicelulose e celulose, como percebe-se pela semelhança dos termogramas destes com o da madeira, enquanto que os produzidos na TA5 aparentam ter perdido a maior parte do teor de hemicelulose, por não apresentar perda significativa de massa abaixo de $290{ }^{\circ} \mathrm{C}$ (Figura 6). A perda de massa dos carvões produzidos acima de $400{ }^{\circ} \mathrm{C}$ se estende por uma ampla faixa de temperatura, evidenciando o contínuo de compostos produzidos durante a pirólise.

A umidade dos carvões deve-se a absorção de água da atmosfera pelas amostras, sendo devida então à higroscopicidade dos carvões (Tabela 2). A higroscopicidade reduziu com o aumento da TP até $600^{\circ} \mathrm{C}$, e teve um aumento nos carvões produzidos em $700^{\circ} \mathrm{C}$, sendo atribuído ao possível aumento da microporosidade dos carvões.

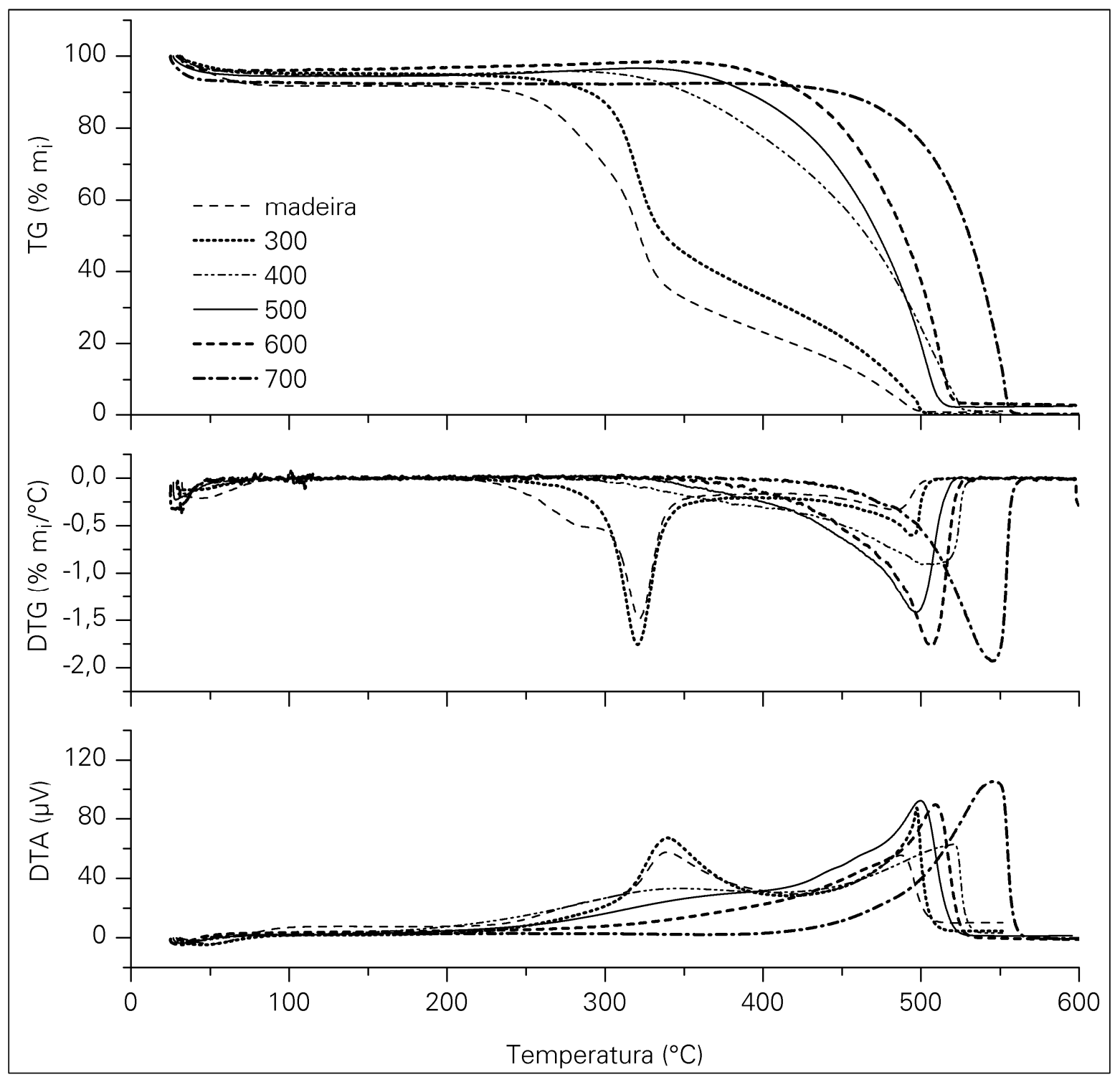

Figura 5. Análise termogravimétrica em atmosfera de ar da madeira e dos carvões produzidos com TA5.

Figure 5. Thermogravimetric analysis in air atmosphere of wood and charcoals produced with TA40. Mi = initial mass. 


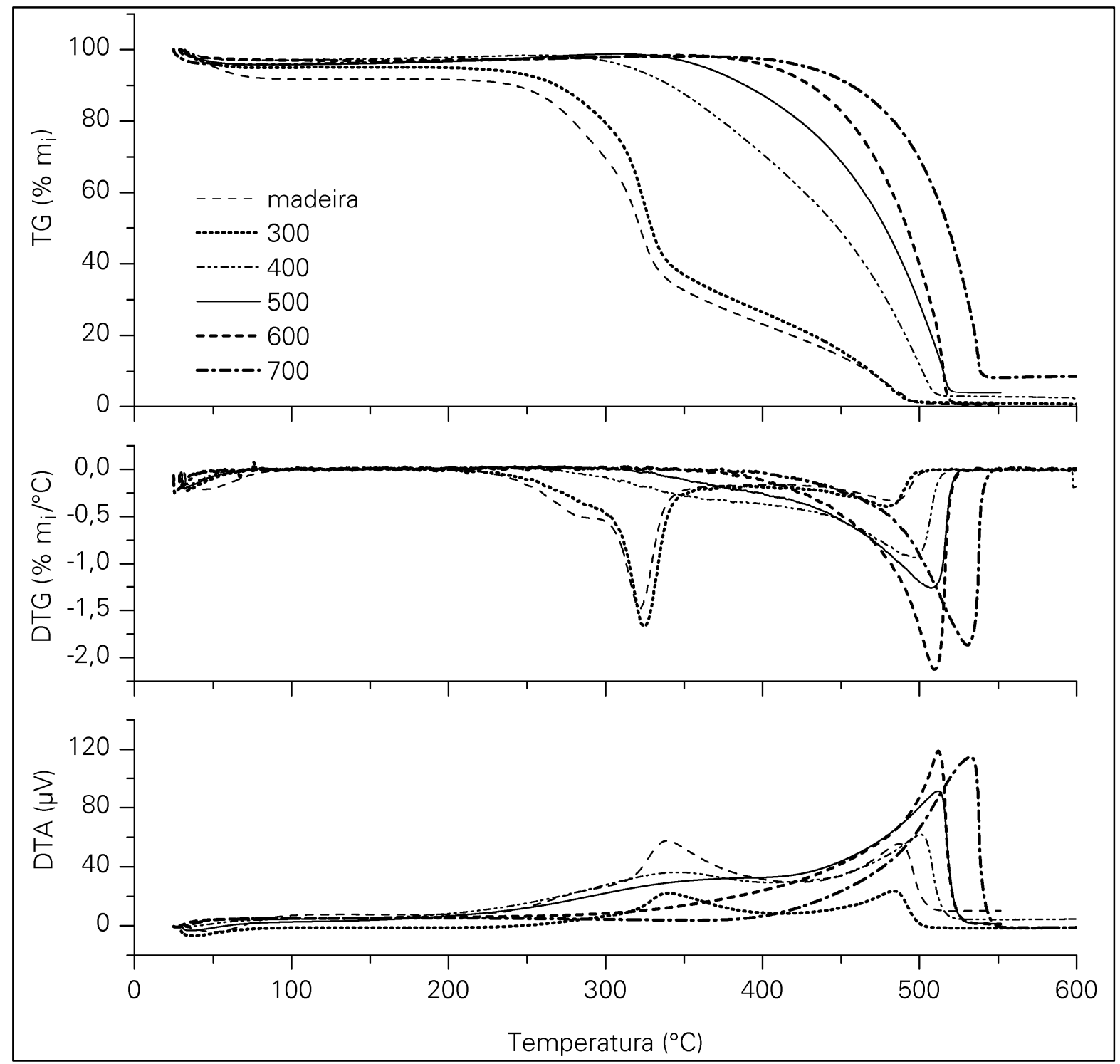

Figura 6. Análise termogravimétrica em atmosfera de ar da madeira e dos carvões produzidos com TA40. $\mathrm{m}_{\mathrm{i}}=$ massa inicial. Figure 6. Thermogravimetric analysis in air atmosphere of wood and charcoals produced with TA40. Mi $=$ initial mass.

Os três índices de estabilidade térmica medidos confirmam o aumento da recalcitrância dos carvões com o aumento dastemperaturas de pirólise (Tabela 2). Os carvões produzidos na TA5 são sistematicamente mais resistentes que os produzidos nas TA22,5 e TA40, enquanto estes praticamente não diferem entre si. A temperatura em que ocorre a máxima taxa de perda de massa no último evento térmico (TUE) aumentou em média $5{ }^{\circ} \mathrm{C}$ para cada aumento de $100{ }^{\circ} \mathrm{C}$ nas temperaturas de pirólise dos carvões produzidos entre 300 e $600^{\circ} \mathrm{C}$, e ocorreu um aumento de $30^{\circ} \mathrm{C}$ na TUE entre os carvões produzidos em $600{ }^{\circ} \mathrm{C}$, para os produzidos em $700{ }^{\circ} \mathrm{C}$.
Esse salto no valor da TUE é um indicativo que estes sofreram uma estabilização diferenciada dos demais carvões. A TUE do carvão produzido na TA 5 em $700{ }^{\circ} \mathrm{C}$, por exemplo, é equivalente ao valor encontrado por Leifeld (2007) para uma amostra de carvão mineral betuminoso. $\mathrm{O}$ alto valor para a TUE do carvão produzido em $400{ }^{\circ} \mathrm{C}$ sob TA5 foi anômalo à tendência geral, podendo ser explicado pela queima inadequada durante a análise, causando a formação de compostos mais estáveis (PLANTE et al., 2009).

Os valores de TUE da madeira e dos carvões foram semelhantes aos encontrados por Cuña Suárez et al. (2010) para a 
Tabela 2. Umidade, temperatura de máxima taxa de perda de massa durante o último evento térmico para os carvões e a madeira.

Table 2. Moisture content, maximum weight loss rate during the final temperature thermal event for charcoal and wood.

\begin{tabular}{|c|c|c|c|c|c|c|c|c|}
\hline \multirow[b]{2}{*}{$\mathbf{T P}$} & \multicolumn{2}{|l|}{ TA5 } & \multicolumn{2}{|c|}{ TA22,5 } & \multicolumn{2}{|c|}{ TA40 } & \multicolumn{2}{|c|}{ Média } \\
\hline & $\begin{array}{c}\mathbf{U} \\
\left.\left(\operatorname{dag~kg}^{-1}\right)^{-}\right)\end{array}$ & $\begin{array}{l}\text { TUE } \\
\left({ }^{\circ} \mathrm{C}\right)\end{array}$ & $\begin{array}{r}\mathrm{U} \\
\left(\text { dag kg }^{-1}\right)\end{array}$ & $\begin{array}{l}\text { TUE } \\
\left({ }^{\circ} \mathrm{C}\right)\end{array}$ & $\begin{array}{r}\mathrm{U} \\
\left(\operatorname{dag~kg}^{-1}\right)\end{array}$ & $\begin{array}{l}\text { TUE } \\
\left({ }^{\circ} \mathrm{C}\right)\end{array}$ & $\begin{array}{r}\mathrm{U} \\
\left(\mathrm{dag} \mathrm{kg}^{-1}\right)\end{array}$ & $\begin{array}{l}\text { TUE } \\
\left({ }^{\circ} \mathrm{C}\right)\end{array}$ \\
\hline Madeira & 7,4 & 485,2 & & 488,6 & 4,5 & 479,1 & 7,4 & 485,2 \\
\hline 300 & 4,3 & 494,8 & 4,5 & 495,3 & 2,7 & 496,5 & 4,4 & 487,5 \\
\hline 400 & 4,5 & 519,6 & 3,5 & 496,1 & 3,5 & 507,4 & 3,6 & $495,9^{\star}$ \\
\hline 500 & 4,3 & 497,0 & 2,6 & 500,3 & 1,4 & 509,8 & 3,5 & 500,2 \\
\hline 600 & 2,7 & 507,0 & 2,3 & 528,7 & 3,1 & 531,0 & 2,1 & 505,7 \\
\hline 700 & 5,4 & 545,2 & 2,6 & 528,7 & 3,1 & 531,0 & 3,7 & 535,0 \\
\hline Média & 4,2 & 512,7 & 3,1 & 501,8 & 3,0 & 504,8 & & \\
\hline
\end{tabular}

Legenda: TP: temperatura de pirólise; TA: taxa de aquecimento; U: umidade; TUE: último evento térmico * Média dos carvões produzidos na TA22,5 e TA40 apenas.

madeira e carvões de Eucalyptus dunnii produzidos nas mesmas temperaturas de pirólise que neste estudo, mas com TA de $4{ }^{\circ} \mathrm{C} / \mathrm{min}$ e mantendo as amostras na maior temperatura por $2 \mathrm{~h}$. Este fato sugere que a TP é um fator mais importante para a estabilidade térmica dos carvões, do que a taxa de aquecimento e tempo de pirólise.

O incremento da estabilidade térmica do carvão com o aumento da TP em que é produzido, também tem de ser considerada. Um maior valor da TUE pode ser interpretado como um aumento da energia de ativação necessária para promover a quebra das ligações químicas de um composto. Portanto, o aumento da TUE provavelmente deve implicar num maior tempo em que o C é mantido na forma estabilizada.

\section{Conclusões}

- O uso de maior taxa de aquecimento permitiu um aumento do líquido pirolenhoso;

- O rendimento gravimétrico do carvão foi menor com o aumento da temperatura final de pirólise.

- Com o aumento da taxa de aquecimento, ocorre maior ruptura da estrutura do carvão, reduzindo a sua resistência física;
- A temperatura em que é realizada a pirólise exerce maior influência sobre as propriedades físicas do carvão do que a taxa de aquecimento

\section{Agradecimento}

Ao Conselho Nacional de Desenvolvimento Científico e Tecnológico (CNPq), pelo apoio financeiro e pela concessão da bolsa de estudo.

\section{Referências}

BOEHM, H.P. Surface chemical characterization of carbons from adsorption studies. In: BOTTANI, EJ, TASCÓN, JMD eds. Adsorption by carbons. Elsevier, v.8, p.301-328, 2008.

BYRNE, C.E; NAGLE, D.C. Carbonized wood monolithscharacterization. Carbon, v.35, p.267-273, 1997.

CUÑA SUÁREZ, A.; TANCREDI, N.; PINHEIRO, P.C.C.; YOSHIDA, M.I. Thermal analysis of the combustion of charcoal from Eucalyptus dunnii obtained at different pyrolysis temperatures. Journal of Thermal Analysis and Calorimetry, v.100, p.1051-1054, 2010.

DEMIRBAS, M.F. Biorefineries for biofuel upgrading: A critical review. Applied Energy, v.86, p.151-161, 2009.

GARCIA-PEREZ, M.; WANG, S.; SHEN, J.; RHODES, M.J.; LEE, W.J.; LI, C. Effects of temperature on the formation of 
lignin-derived oligomers during the fast pyrolysis of Mallee woody biomass. Energy Fuels, v.22, p.2022-2032, 2008.

GŁĄB. T; PALMOWSKA, J.; ZALESKI, T.; GONDEK, K. Effect of biochar application on soil hydrological properties and physical quality of sandy soil. Geoderma, v. 281, p.11-20, 2016.

HEIN, P.R.; CAMPOS, A.C.M.; TRUGILHO, P.F.; LIMA, J.T.; CHAIX, G. Near infrared spectroscopy for estimating wood basic density in Eucalyptus urophylla and Eucalyptus grandis. Cerne, Lavras, v. 15, n. 2, p. 133-141, 2009.

HERATH, H.M.S.K., CAMPS-ARBESTAIN, M., HEDLEY, M. Effect of biochar on soil physical properties in two contrasting soils: an Alfisol and an Andisol. Geoderma, v.209, p. 188-197, 2013.

LEHMANN, J.; JOSEPH, S. Biochar for environmental management: an introduction. In: Lehmann J., Joseph S eds. Biochar for environmental management: science and technology., Earthscan, v.52, p.1-12, 2009.

LEIFELD, J. Thermal stability of black carbon characterised by oxidative differential scanning calorimetry. Organic Geochemistry, v. 38, p.112-127. 2007.

OLIVEIRA, Y.C; CARNEIRO, A.C.O.; VITAL, B.R.; ALMEIDA, W.; PEREIRA, B.L.C.; CARDOSO, M.T. Parâmetros de qualidade da madeira e do carvão vegetal de Eucalyptus pellita F. Muell. Scientia Florestalis, v. 38, n. 87, p. 431-439, 2010.

PLANTE, A.F.; FERNÁNDEZ, J.M.; LEIFELD, J. Application of thermal analysis techniques in soil science. Geoderma, v.153, p.1-10, 2009.

RANZI, E.; CUOCI, A.; FARAVELLI, T.; FRASSOLDATI, A.; MIGLIAVACCA, G.; PIERUCCI, S.;SOMMARIVA, S. Chemical kinetics of biomass pyrolysis. Energy Fuels, v.22, p.4292-4300, 2008.

ROWELL, R.M.; PETTERSEN, R.; HAN, J.S.; ROWELL, J.S.; TSHABALALA, M.A. Cell wall chemistry. In: ROWELL, R.M., ed. Handbook of wood chemistry and wood composites. CRC Press, v.21, p. 35-74, 2005.

VALENTE, O. F.; ALMEIDA, J. M.; VITAL, B. R.; DELLA LUCIA, R. M. Efeito da temperatura de carbonização nos rendimentos e propriedades do carvão vegetal produzido. Revista Árvore, v. 9, n. 1, p. 28-39, 1985.
VIEIRA, R.S.; LIMA, J.T.; MONTEIRO, T.C.; SELVATTI, T.S.; BARAÚNA, E.E.P.; NAPOLI, A. Influência da temperatura no rendimento dos produtos da carbonização de $E$ calyptus microcorys. Cerne, vol.19, p.59-64, 2013.

WINANDY, J.E.; ROWELL, R.M. Chemistry of wood strength. In: ROWELL, R.M., ed. Handbook of wood chemistry and wood composites. Boca Raton, CRC Pres, v.21, p.303-347, 2005.

WOOTEN, J.B. SEEMAN, J.I.; HAJALIGOL, M.R. Observation and Characterization of cellulose pyrolysis intermediates by 13C CPMAS NMR. A new mechanistic model. Energy Fuels, v.18, p.1-15, 2004.

ZHANG, L., CHUNBAO, C., XU, P.C. Overview of recent advances in thermo-chemical conversion of biomass. Energy Conversion and Management. Elsevier, v.51, p.969-982, 2010. 